\title{
Phospho-aspirin (MDC-22) inhibits breast cancer in preclinical animal models: an effect mediated by EGFR inhibition, p53 acetylation and oxidative stress
}

Liqun Huang ${ }^{1}$, Chi C Wong ${ }^{1}$, Gerardo G Mackenzie', Yu Sun ${ }^{1}$, Ka Wing Cheng ${ }^{1}$, Kvetoslava Vrankova ${ }^{1}$, Ninche Alston", Nengtai Ouyang ${ }^{1,2}$ and Basil Rigas ${ }^{1 *}$

\begin{abstract}
Background: The anticancer properties of aspirin are restricted by its gastrointestinal toxicity and its limited efficacy. Therefore, we synthesized phospho-aspirin (PA-2; MDC-22), a novel derivative of aspirin, and evaluated its chemotherapeutic and chemopreventive efficacy in preclinical models of triple negative breast cancer (TNBC).

Methods: Efficacy of PA-2 was evaluated in human breast cancer cells in vitro, and in orthotopic and subcutaneous TNBC xenografts in nude mice. Mechanistic studies were also carried out to elucidate the mechanism of action of PA-2.

Results: PA-2 inhibited the growth of TNBC cells in vitro more potently than aspirin. Treatment of established subcutaneous TNBC xenografts (MDA-MB-231 and BT-20) with PA-2 induced a strong growth inhibitory effect, resulting in tumor stasis ( $79 \%$ and $90 \%$ inhibition, respectively). PA-2, but not aspirin, significantly prevented the development of orthotopic MDA-MB-231 xenografts (62\% inhibition). Mechanistically, PA-2: 1) inhibited the activation of epidermal growth factor receptor (EGFR) and suppressed its downstream signaling cascades, including PI3K/AKT/mTOR and STAT3; 2) induced acetylation of p53 at multiple lysine residues and enhanced its DNA binding activity, leading to cell cycle arrest; and 3) induced oxidative stress by suppressing the thioredoxin system, consequently inhibiting the activation of the redox sensitive transcription factor NF-KB. These molecular alterations were observed in vitro and in vivo, demonstrating their relevance to the anticancer effect of PA-2.
\end{abstract}

Conclusions: Our findings demonstrate that PA-2 possesses potent chemotherapeutic efficacy against TNBC, and is also effective in its chemoprevention, warranting further evaluation as an anticancer agent.

Keywords: Breast cancer, Triple-negative breast cancer, Phospho-aspirin, Non-steroidal anti-inflammatory drugs, Epidermal growth factor receptor (EGFR), p53, Oxidative stress

\footnotetext{
*Correspondence: basil.rigas@stonybrookmedicine.edu

${ }^{1}$ Division of Cancer Prevention, Department of Medicine, Stony Brook

University, Stony Brook, New York 11794-8173, USA

Full list of author information is available at the end of the article
} 


\section{Background}

Breast cancer is the second most common cause of female cancer-related deaths, with more than one million new cases diagnosed per year throughout the world [1]. Despite advances in its early detection, breast cancer remains a significant health problem. In particular, triple negative breast cancer (TNBC) is known to be more aggressive with poor prognosis, and is frequently associated with resistance to chemotherapeutic agents. Thus, novel agents capable of inhibiting TNBC are urgently needed.

Aspirin, a prototypical non-steroidal anti-inflammatory drug (NSAID), is the most widely used anti-inflammatory medication in the world $[2,3]$. NSAIDs have a significant antineoplastic effect, which should be viewed, at least in part, in the context of the increasingly appreciated role of inflammation in cancer. Aspirin has been formally documented to be a chemopreventive agent against colon cancer $[4,5]$. Epidemiological studies also support a role of aspirin in reducing the risk of breast cancer [6]. However, gastrointestinal toxicity caused by chronic aspirin use is a significant health concern. In order to reduce the toxicity and enhance the efficacy of aspirin, we synthesized phospho-aspirin (PA-2; MDC-22; Figure 1A), which consists of aspirin chemically modified at its $-\mathrm{COOH}$ group, the moiety accounting for its gastrointestinal toxicity $[7,8]$. Indeed, as we have recently reported, the gastrointestinal toxicity of PA-2 in rats is much reduced compared to that of aspirin [9].

The epidermal growth factor receptor (EGFR) and p53 are key molecular determinants of TNBC [10-12]. Aberrant activation of EGFR plays an important role in breast carcinogenesis via the sustained initiation of downstream cascades that promote cell survival and proliferation. Thus, EGFR is an attractive target for the development of cancer therapeutics [13]. On the other hand, the inactivation of $\mathrm{p} 53$, a potent tumor suppressor, is also a major contributor to breast cancer development [12]. Apart from its ability to block cell cycle progression and promote apoptosis, it is now appreciated that p53 also suppresses tumor development by modulating autophagy, cellular metabolism, angiogenesis, and metastasis [14]. This portends that the restoration of $\mathrm{p} 53$ function in tumors will be extremely beneficial, since it will not merely inhibit the growth of tumor cells but also obliterate the microenvironment required for tumor survival.

Herein, we examined the antineoplastic properties of PA-2 in TNBC in vitro and in vivo. PA-2 was much more potent than aspirin in inhibiting the growth of TNBC cells and strongly suppressed TNBC growth in subcutaneous and orthotopic xenograft models. Mechanistically, the antineoplastic effect of PA-2 is mediated through inhibition of EGFR, acetylation of p53 and induction of oxidative stress.

\section{Methods \\ Reagents}

PA-2 was provided by Medicon Pharmaceuticals, Inc., Setauket, NY. Aspirin were purchased from Sigma (St Louis, MO). For cell culture study, we prepared $500 \mathrm{mM}$ stock solutions of both in DMSO. In all cell culture media, the final DMSO concentration was adjusted to 1\%. All general solvents and reagents were of HPLC grade or of the highest grade commercially available. Antibodies against $\beta$-actin were from Sigma. All other antibodies were from Cell Signaling (Beverly, MA).

\section{Cell culture}

We used three human breast cancer cell lines: MDAMB 231 (ER-, PR-, HER2/Neu-, EGFR+, and p53 mutant R280K), BT-20 ( ER-, PR-, HER2/Neu-, EGFR++, and p53 mutant K132G), and MDA-MB-468 (ER-, PR-, HER2/Neu-, EGFR++, and p53 mutant R2073H). All were obtained from the American Type Culture Collection (ATCC, Manassas, VA, and grown as monolayers in the specific medium and conditions suggested by ATCC. All cell lines were grown in our laboratory less than 6 months after their receipt and the cells studied were between passages 2-10.

\section{Cell viability assay}

We used an assay based on reduction of 3-(4,5-dimethylthiazol-2-yl)-2,5-diphenyltetrazolium bromide dye (MTT), which was determined according to the manufacturer's protocol (Promega, Madison, WI).

\section{Cytokinetic analysis}

For apoptosis, cells were seeded and treated with PA-2 for $24 \mathrm{~h}$, trypsinized and stained with Annexin V-FITC (100X dilution; Invitrogen, Carlsbad, CA) and PI (0.5 $\mu \mathrm{g} / \mathrm{ml}$; Sigma, St Louis, MO), then analyzed by FACScaliber (BD Biosciences, San Jose, CA). To determine cell proliferation, we measured the incorporation of 5bromo-2'-deoxyuridine (BrdU) into newly synthesized cellular DNA followed by the manufacture's protocol (BD Biosciences), and cells were subjected to flow cytometric analysis. Cell cycle phase distribution was analyzed by flow cytometry as described [15].

\section{Plasmid and siRNA transfection}

EGFR, and SIRT1 plasmids were purchased from Addgene (Cambridge, MA). Transient transfection was performed with Lipofectamine 2000 (Invitrogen, Carlsbad, CA) following the manufacturer's instructions. 


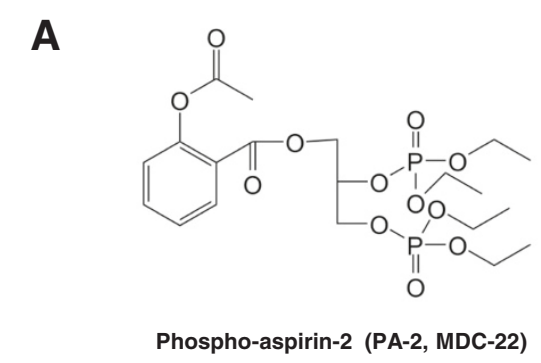

\begin{tabular}{cccc}
\hline \multicolumn{4}{c}{$24 \mathrm{~h} \mathrm{IC}_{50}, \mu \mathrm{M}$} \\
(fold enhancement over parent compound) \\
\hline Drug & MDA-MB-468 & MDA-MB-231 & BT-20 \\
\hline Aspirin & $>1,500$ & $>2,000$ & $>2000$ \\
\hline PA-2 & $198(>7)$ & $360(>6)$ & $440(>5)$ \\
\hline
\end{tabular}
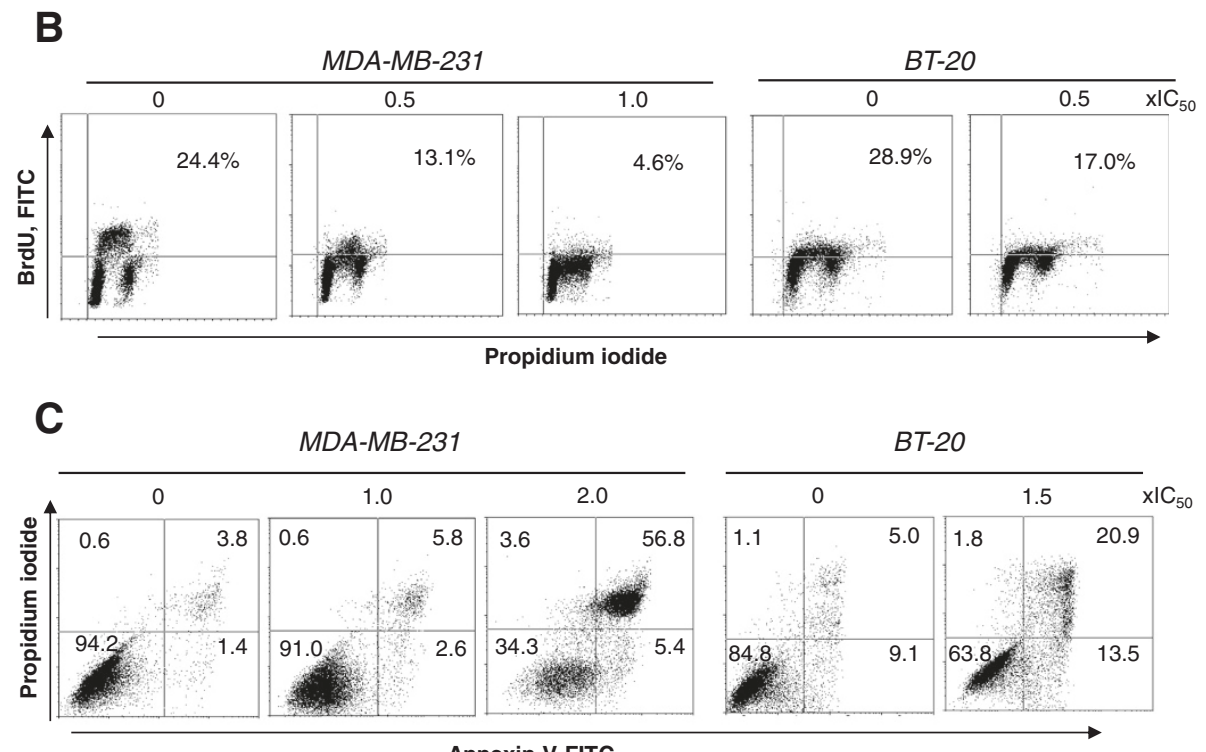

Annexin V-FITC

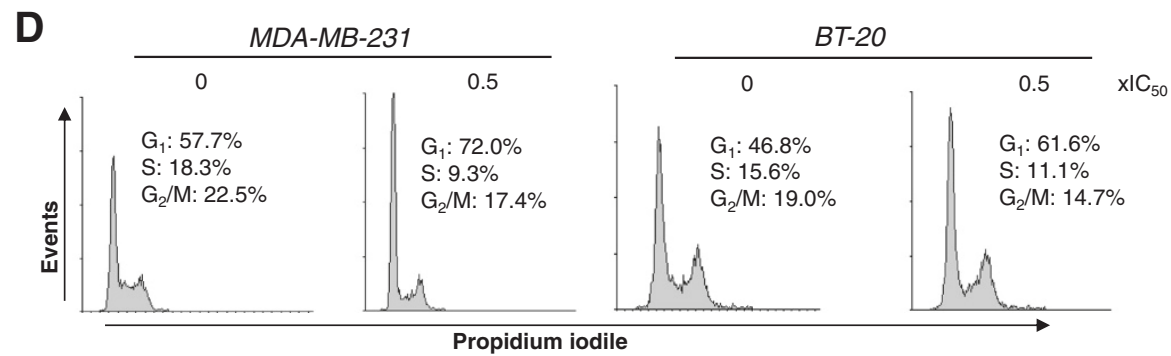

Figure 1 Phospho-aspirin-2 inhibits the growth of TNBC cells. A: Left: Chemical structure of phospho-aspirin-2 (PA-2, MDC-22). Right: $24 \mathrm{~h}-\mathrm{IC}_{50}$ values of PA-2 and aspirin in TNBC cell lines. B: MDA-MB-231 and BT-20 cells were treated with PA-2 for $24 \mathrm{~h}$ and the percentage of proliferating cells was determined by BrdU incorporation. C: MDA-MB-231 and BT-20 cells treated with PA-2 for $24 \mathrm{~h}$ were stained with Annexin V/PI, and the percentage of apoptotic cells was determined by flow cytometry. D: PA-2 blocks the $G_{1} / S$ cell cycle phase transition after $24 \mathrm{~h}$ treatment in MDA-MB-231 cells, determined by flow cytometry following PI staining.

\section{Determination of reactive oxygen and nitrogen species (RONS)}

After the indicated treatment, cells were collected by trypsinization, resuspended in $10 \mu \mathrm{M}$ of 5 -(and-6)carboxy-2',7'-dichlorodihydrofluorescein diacetate ( $\mathrm{H}_{2}$ DCFDA Invitrogen), or MitoSox Red (Invitrogen) or dihydroethidium (DHE, Sigma), incubated at $37^{\circ} \mathrm{C}$ for $30 \mathrm{~min}$ in the dark and their fluorescence intensity was determined by flow cytometry.

\section{Urinary $F_{2}$ isoprostane assay}

Urine was collected at the endpoint of treatment. Levels of $\mathrm{F}_{2}$ isoprostane and creatinine in urine were determined by ELISA (Oxford Biomedical Research, MA). F2isoprostane values were normalized to creatinine levels.

\section{Determination of TrxR reductase activity}

After treatment, cells were lysed and TrxR activity was determined in the protein lysate using a commercially 
available kit, following the instructions of the manufacturer (Cayman Chemical, Ann Arbor, MI). In this assay, TrxR uses NADPH to reduce 5,5'-dithiobis-(2-nitrobenzoic acid) to 5-thio-2-nitrobenzoic acid (TNB). Glutathione (oxidized and reduced) was determined by the glutathione $(\mathrm{GSH})$ reductase-coupled 5,5' -dithiobis (2-nitrobenzoic acid) assay [16].

\section{Immunoblotting}

After treatment with PA-2 as indicated, cells were scraped on ice, washed with ice-cold PBS and lysed in RIPA lysis buffer (Sigma). Protein concentration was determined using the Bradford method (Bio-Rad, Hercules, CA). Electrophoresis of cell lysates were performed on $10 \%$ SDS-polyacrylamide gel electrophoresis gels and protein was transferred onto nitrocellulose membranes as described [17];

\section{Electrophoretic Mobility Shift Assay (EMSA)}

Following treatment, nuclear fractions were isolated from $2 \times 10^{6}$ cells as described [16]. NF-kB, or p53 EMSA was performed according to The Thermo Scientific LightShift Chemiluminescent EMSA Kit (Rockford, IL) following the instructions of the manufacturer.

\section{Efficacy studies in nude mouse breast xenografts and orthotopic model}

All animal experiments were approved by the Institutional Animal Care and Use Committee.

\section{Treatment protocol}

Female Balb/C nude mice (Charles River Laboratories, Wilmington, MA) were inoculated subcutaneously into each of their flanks with 2.5-3 × $10^{6}$ TNBC cells (MDAMB-231 or BT-20) in Matrigel (BD Biosciences, Franklin Lakes, NJ). When the tumor reached approximately 100$150 \mathrm{~mm}^{3}$, animals were randomized into the control and treatment groups $(n=10 /$ group $)$. For MDA-MB-231 xenografts, the animals were treated with vehicle or PA$2120 \mathrm{mg} / \mathrm{kg}$ p.o. in corn oil 5 times/wk. For BT-20 xenografts, animals were treated with vehicle or PA-2 300 $\mathrm{mg} / \mathrm{kg}$ i.p. in corn oil 5 times/wk.

\section{Prevention protocol}

Female Balb/C nude mice were treated with PA-2 120 $\mathrm{mg} / \mathrm{kg}$ or ASA $40 \mathrm{mg} / \mathrm{kg}$ p.o. in corn oil (equimolar) for $1 \mathrm{wk}$. Then, the mice were inoculated into the mammary fat pad with $1.0 \times 10^{6}$ MDA-MB-231 cells in Matrigel. Drug treatment was continued until the end of the study. Tumor volume was calculated as [length $\times$ width $\times($ length + width $/ 2) \times 0.56]$. At the end of treatment, animals were sacrificed and tumors were removed and weighed. To calculate tumor growth inhibition, we subtracted the baseline tumor volume from the final one.

\section{Immunohistochemical analysis}

Immunohistochemical staining for Ki-67, Dmp1 and phospho-NF- $\mathrm{kB}$ (p-p65, activated form of NF- $\mathrm{kB}$ ) was performed on human breast xenograft tissue samples as previously described [18]. Apoptosis was determined by the terminal deoxynucleotidyl transferasemediated deoxyuridine triphosphate-biotin nick endlabeling (TUNEL) assay [19].

\section{Statistical analysis}

Results are expressed as mean \pm SEM. Differences between groups were determined by one-factor analysis of variance followed by Tukey's test for multiple comparisons. $\mathrm{p}<0.05$ was statistically significant.

\section{Results}

PA-2 inhibits the growth of human TNBC through a strong cytokinetic effect

We first compared the growth inhibitory effect of PA-2 and aspirin in a panel of TNBC cell lines. PA-2 inhibited cell growth more potently than aspirin in all the cell lines evaluated. The potency enhancement ranged between 5 and 7-fold in MDA-MB-231, MDA-MB-468, and BT-20 (Figure1A). PA-2 inhibited TNBC cell growth via a triple cytokinetic effect. In MDA-MB-231 and BT20 cells, PA-2 a) inhibited cell proliferation by $>40 \%$ at $0.5 \times \mathrm{IC}_{50}$ and by $>80 \%$ at $1 \times \mathrm{IC}_{50}$; b) induced apoptosis by 1.6 - to 12 -fold over control at 1.5 -and $2 \times \mathrm{IC}_{50}$; and $c$ ) suppressed the $G_{1}$ to $S$ cell cycle phase transition, leading to accumulation of cells in $\mathrm{G}_{1}$ phase by $14 \%$ at $0.5 \times \mathrm{IC}_{50}$ (Figure1B-D).

To assess the efficacy of PA-2 in vivo, we employed both subcutaneous and orthotopic TNBC xenografts in nude mice. Initially, we evaluated the chemotherapeutic effect of PA-2 on subcutaneous MDA-MB-231 and BT20 xenografts. As shown in Figure 2A, PA-2 significantly inhibited MDA-MB-231 xenograft growth starting on day 8 of treatment until the end of the study ( $p$ $<0.001)$. At sacrifice, the tumor volume of vehicle was $309 \pm 36 \mathrm{~mm}^{3}$ and that of PA-2 was $143 \pm 16 \mathrm{~mm}^{3}$, representing a $79 \%$ tumor growth inhibition $(\mathrm{p}<0.01)$. PA-2 also suppressed the growth of BT-20 xenografts (Figure 2B). After 28 days of treatment, the tumor volume of vehicle and PA-2 groups were $248 \pm 27 \mathrm{~mm}^{3}$ and $157 \pm 15 \mathrm{~mm}^{3}$, respectively (90\% inhibition, $\mathrm{p}<0.01$ ).

We next evaluated the chemopreventive effect of PA-2 and compared it to aspirin, its parent compound. Following a prevention protocol, we treated nude mice bearing orthotopically implanted MDA-MB-231 xenografts with equimolar doses of PA-2 or aspirin starting 1 week before tumor implantation. On day 66 postimplantation, PA-2 inhibited the development of primary tumor in the mammary fat pads by $62 \%(\mathrm{p}<0.05$; Figure $2 \mathrm{C}$ ). In contrast, aspirin had no significant effect 


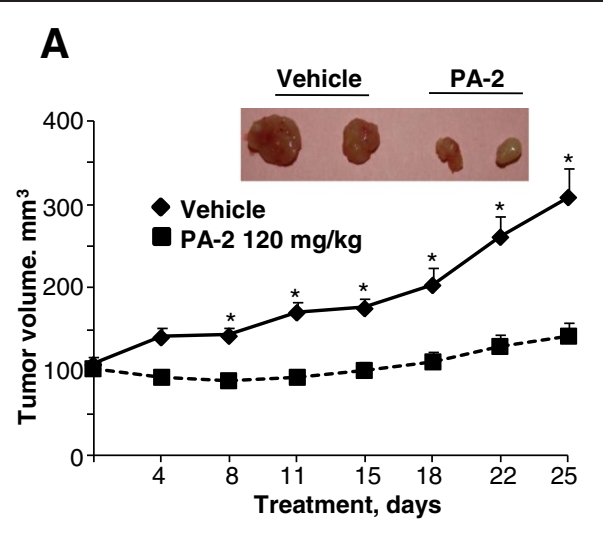

B
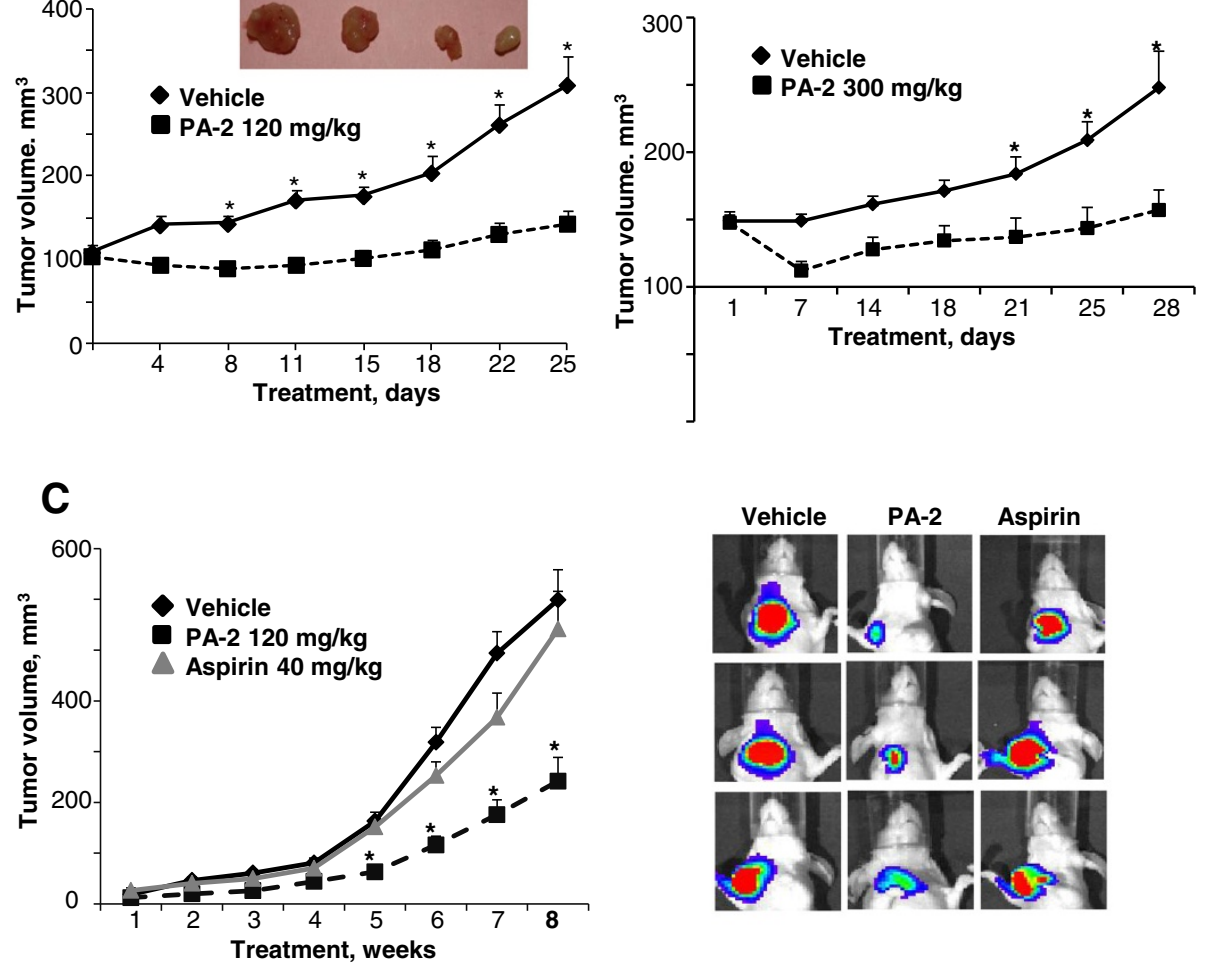

D
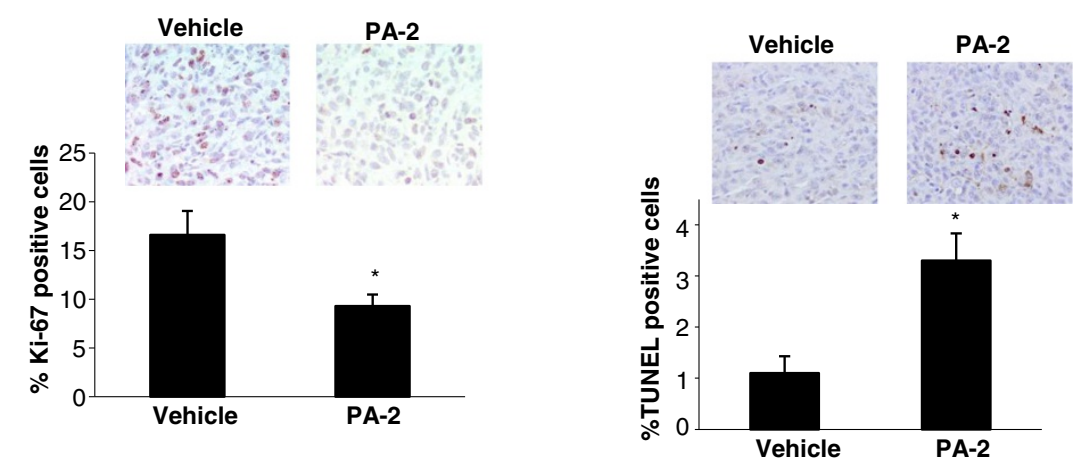

Figure 2 Phospho-aspirin-2 inhibits the growth of TNBC xenografts. A: Chemotherapeutic effect of PA-2 on subcutaneous MDA-MB-231 xenografts in nude mice. Two representative tumors from each group are shown. ${ }^{*}, p<0.001$, compared to vehicle; $n=10-16$ tumors/group. B: Chemotherapeutic effect of PA-2 on subcutaneous BT-20 xenografts in nude mice. ${ }^{*}, p<0.01$, compared to vehicle; $n=10-16$ tumors/ group. C: Chemopreventive effect of PA-2. Nude mice bearing orthotopic xenografts of MDA-MB-231 cells were treated with PA-2 or aspirin for $9 \mathrm{wks}$, starting $1 \mathrm{wk}$ before cell implantation. The tumor volumes of the orthotopic MDA-MB-231 xenografts at sacrifice were determined by luciferase in vivo imaging as described in the methods section. Representative tumors from each group are shown. ${ }^{*}, p<0.05$, compared to vehicle. D: Cytokinetic effect of PA-2 in MDA-MB-231 xenografts (treatment protocol). Left: Representative images (top) and the quantification (bottom) of Ki-67 expression in tumor sections, ${ }^{*} p<0.01$. Right: Representative images (top) and the quantification (bottom) of TUNEL positive cells in tumor sections, ${ }^{*} \mathrm{p}<0.002$. All values are mean $\pm \mathrm{SEM}$.

on breast tumor growth in this orthotopic model, consistent with previous findings [20].

We also determined cell proliferation and apoptosis in MDA-MB-231 xenografts in the treatment study (Figure 2A) using Ki-67 staining and TUNEL assay, respectively (Figure 2D). Compared to the vehicle, PA-2 inhibited cell proliferation by $44 \%(\mathrm{p}<0.01)$ and increased apoptosis by 3 -fold $(\mathrm{p}<0.002)$. This indicates that PA-2 also exerted a cytokinetic effect on TNBC xenografts in vivo. 
PA-2 modulates the phosphorylation status of EGFR, p53 and NF-KB

To elucidate the mechanisms of action of PA-2, we performed antibody microarray analyses (Kinexus, Vancouver, Canada) on MDA-MB-231 cells treated with vehicle or PA-2 $1.5 \times \mathrm{IC}_{50}$ for $2 \mathrm{~h}$. This assay revealed pronounced changes in EGFR, p53 and NF-kB pathways following PA-2 treatment (Additional file 1: Table S1).
Therefore, we further investigate the contribution of each of these pathways to the anti-cancer effect of PA-2.

\section{PA-2 inhibits EGFR activation and its downstream} signaling

EGFR is known to correlate with the progression of TNBC [11]. In MDA-MB-231 and BT-20 cells, PA-2 inhibited EGFR phosphorylation in a time-dependent

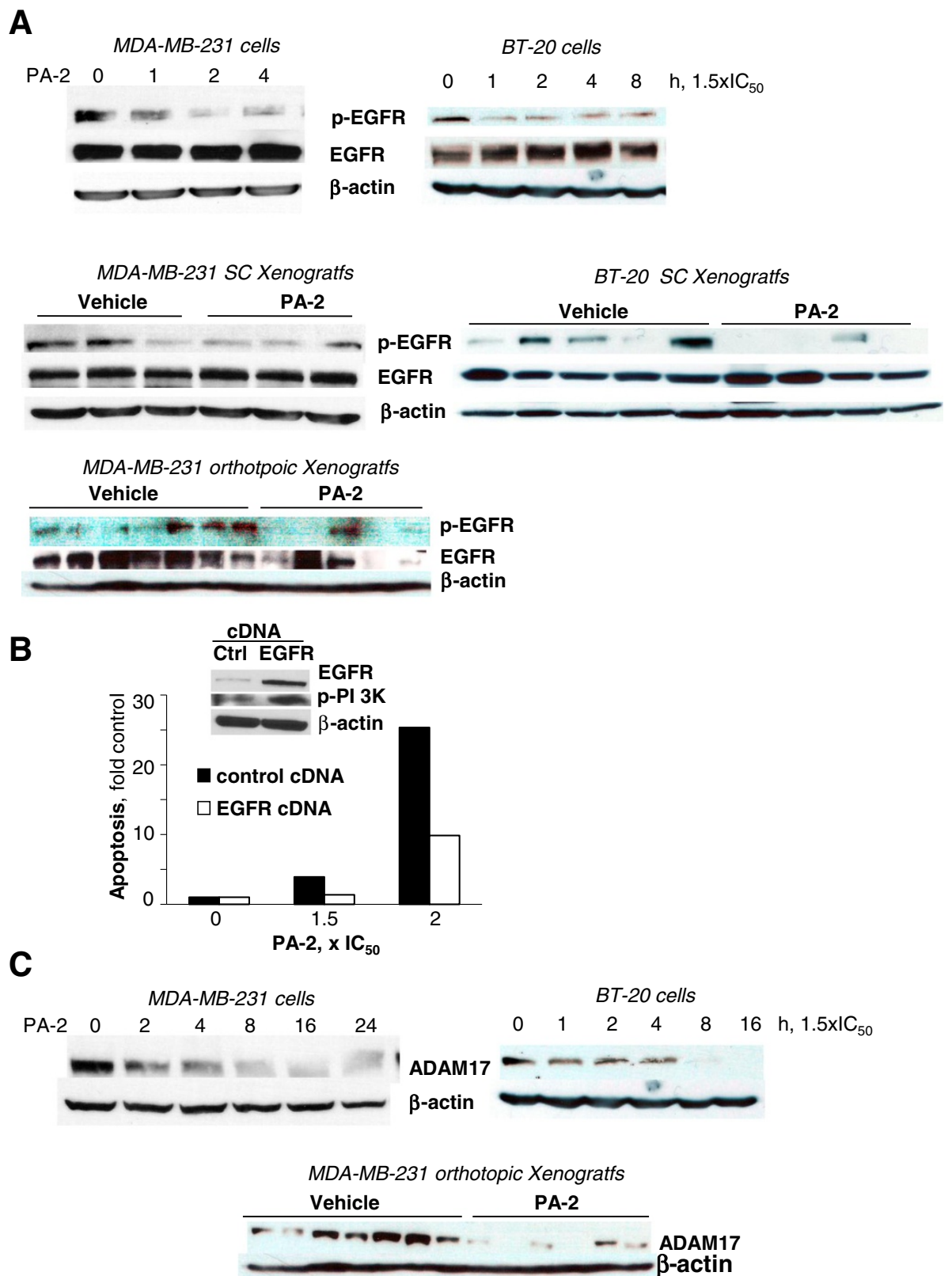

Figure 3 Phospho-aspirin-2 inhibits EGFR phosphorylation. A: Upper: PA-2 $1.5 \times I C_{50}$ inhibited the expression of p-EGFR in MDA-MB-231 and BT-20 cells. Lower: PA-2 treatment inhibited the expression of p-EFGR in MDA-MB-231 and BT-20 xenografts $(p<0.05)$. B: Effect of PA-2 at various concentrations on apoptosis in EGFR overexpressing MDA-MB-231 cells or their mock transfected control. Western blot confirmed the overexpression of EGFR and increased levels of p-PI3K. C: PA-2 suppressed ADAM17 levels in MDA-MB-231 and BT-20 cells in vitro and in MDA-MB-231 orthotopic xenografts $(p<0.05)$. In all panels, immunoblots were performed with $\beta$-actin as loading control. 
manner, being evident as early as $1 \mathrm{~h}$ after treatment (Figure 3A). This observation was confirmed in vivo, where PA-2 reduced EGFR phosphorylation by $68 \%$ and $83 \%$ in MDA-MB-231 and BT-20 xenografts, respectively, compared to controls $(\mathrm{p}<0.05$, Figure $3 \mathrm{~A})$.

To determine the role of EGFR inhibition in the anticancer effect of PA-2, we transiently transfected MDAMB-231 cells with an EGFR-overexpressing plasmid, and evaluated whether PA-2-induced cell death was affected. EGFR overexpression and activation of its downstream target p-PI3K was confirmed by western blot (Figure 3B). EGFR overexpression suppressed the induction of apoptosis by PA-2. Compared to mock transfected control, EGFR-overexpressing MDA-MB231 cells have 2.5 -fold reduction in the annexin $\mathrm{V}(+)$ fraction after treatment with PA-2 $2 \mathrm{xIC}_{50}$ (Figure $3 \mathrm{~B}$ ). This indicates that EGFR inhibition is an important mechanism of action of PA-2, and the reversal of this effect mediates drug resistance.

An important upstream regulator of EGFR phosphorylation is ADAM17, which activates EGFR through a ligand cleavage mechanism [21]. We assessed the effect of PA-2 on ADAM proteins. As shown in Figure $2 \mathrm{C}$, in MDA-MB231 and BT-20 cells, PA-2 reduced the

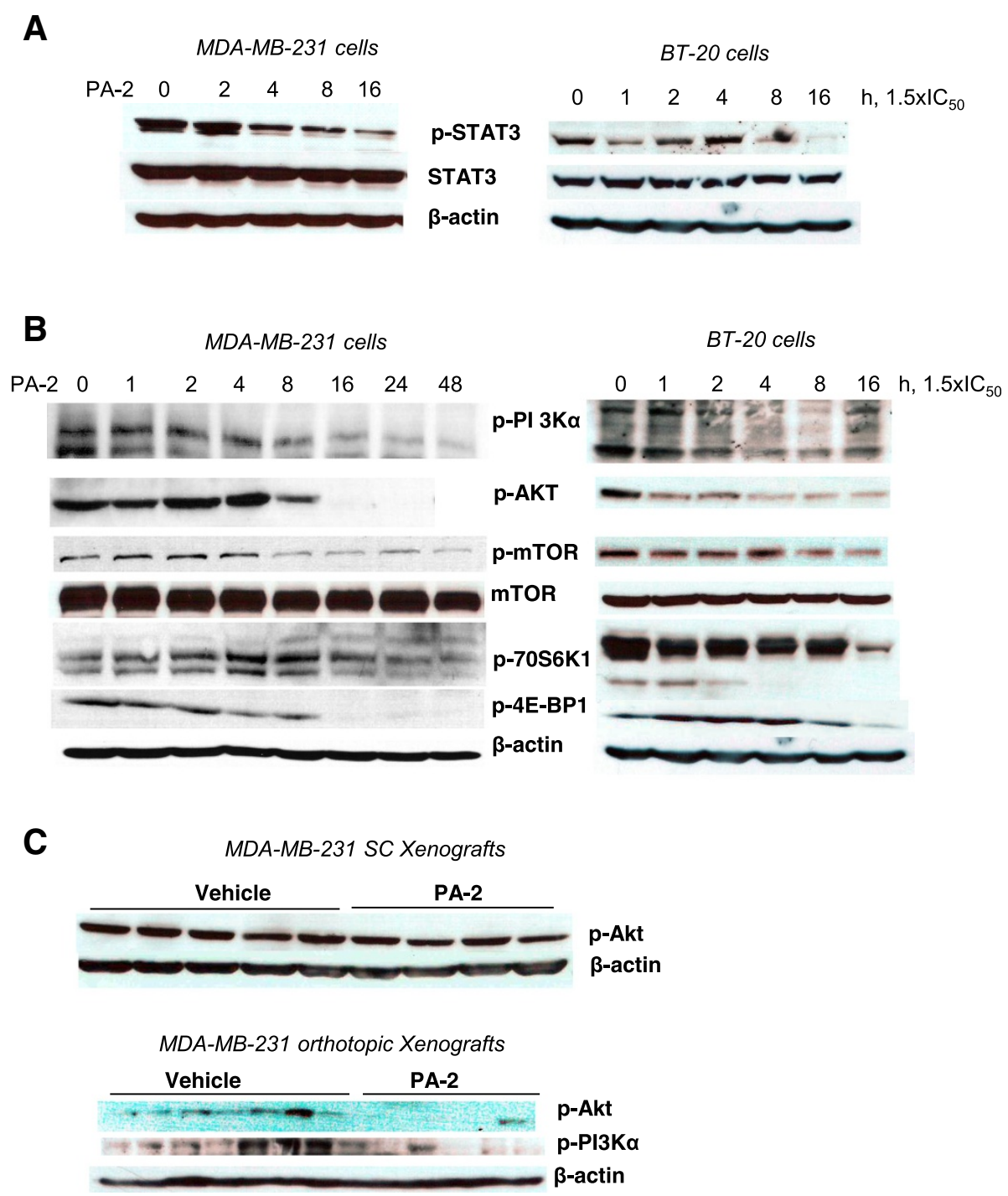

Figure 4 Phospho-aspirin-2 inhibits EGFR downstream signaling. A. PA-2 $1.5 \times I C_{50}$ inhibited STAT3 phosphorylation in MDA-MB-231 and BT-20 cells in a time-dependent manner. B: PA-2 treatment resulted in the sequential inactivation of PI3K signaling cascade, as indicated by the time-dependent reduction of the expression of p-PI3K, p-Akt, p-mTOR, p-p70S6K and p-4E-BP-1 in MDA-MB-231 and BT-20 cells. C: PA-2 reduced p-Akt expression in subcutaneous (treatment protocol) and orthotopic (prevention protocol) MDA-MB-231 xenografts. In all panels, immunoblots were performed with $\beta$-actin as loading control. 


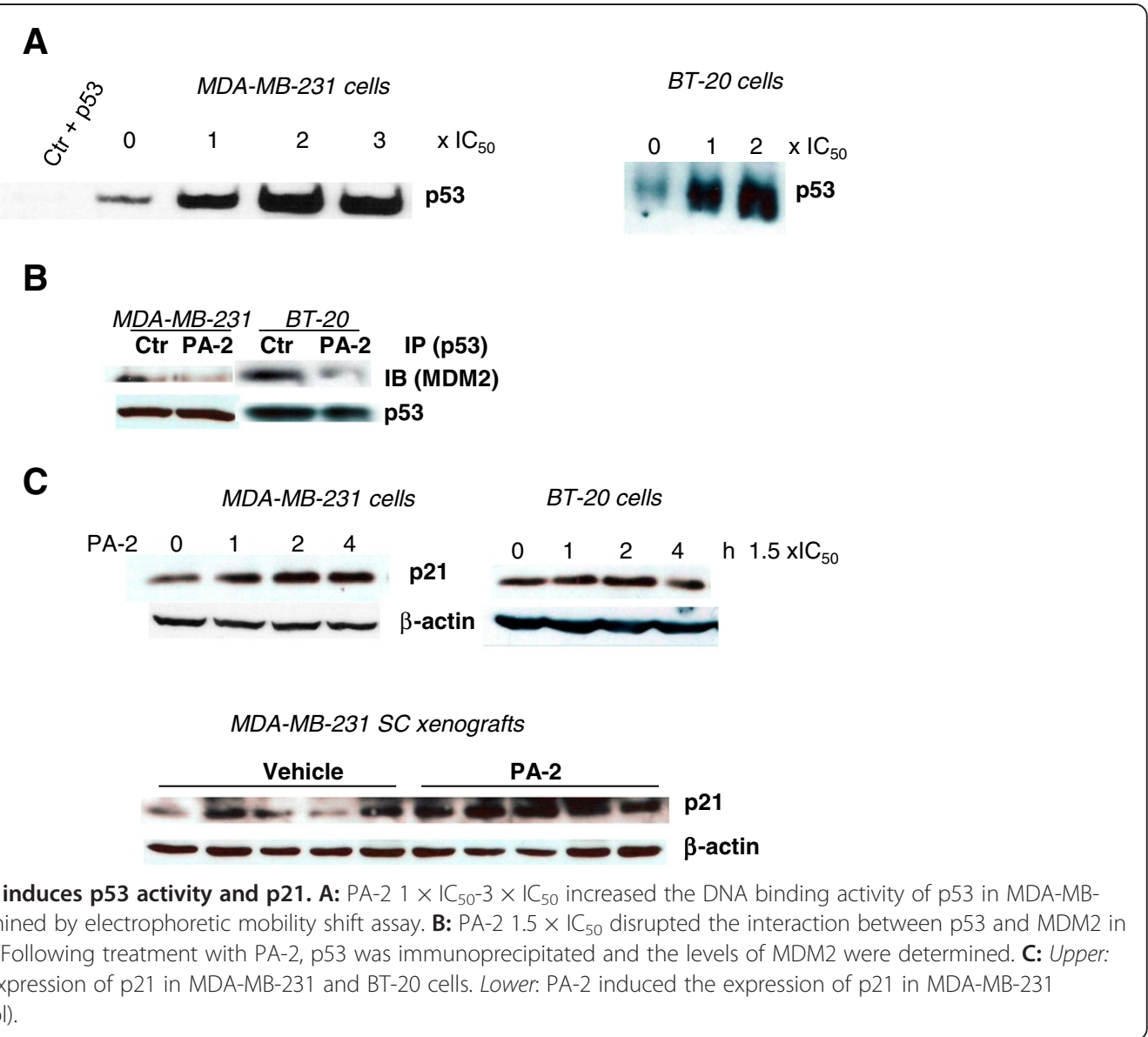

expression of ADAM17. Moreover, PA-2 suppressed the levels of ADAM17 in MDA-MB-231 orthotopic xenografts.

Inhibition of EGFR activation resulted in a potent inhibitory effect on its downstream signaling cascades, STAT3 and PI3K/Akt pathways. PA-2 reduced STAT3 phosphorylation in MDA-MB-231 and BT-20 cells (Figure 4A). PA-2 also suppressed the levels of p-PI3K and $\mathrm{p}$-Akt in these cells in vitro (Figure $4 \mathrm{~B}$ ) and in MDAMB-231 xenografts (Figure 4C). In addition, the downstream targets of PI3K/Akt pathway, including p-mTOR, $\mathrm{p}-4 \mathrm{E}-\mathrm{BP} 1$ and $\mathrm{p}-70 \mathrm{~S} 6 \mathrm{~K} 1$, were reduced after prolonged (16h) PA-2 treatment (Figure 4B). Hence, PA-2 triggered a temporal suppression of EGFR signaling cascades in TNBC.

\section{PA-2 induces acetylation of p53 and cell cycle arrest}

The tumor suppressor gene p53 is frequently inactivated in TNBC [22]. In MDA-MB-231 and BT-20 cells, PA-2 enhanced the DNA-binding activity of p53 in a concentration-dependent manner (Figure 5A). PA-2 did not appear to alter the nuclear shuttling of p53 (Figure 5A). On the other hand, immunoprecipitation showed that PA-2 significantly reduced the binding of p53 to murine double minute 2 (MDM2) (Figure 5B). Dissociation of p53 from MDM2, which otherwise binds to p53 and represses its transcriptional activity [23], may therefore contribute to the induction of p53 DNA binding activity by PA-2 in TNBC cells. The activation of $\mathrm{p} 53$ by PA- 2 was consequential, as PA-2 blocked $G_{1}$ to $S$ cell cycle transition (Figure 1D) and up-regulated p21 in TNBC cells in vitro and in MDA-MB-231 xenografts (Figure 5C).

Acetylation of p53 at lysine residues is critical for its stability and transcriptional activity [24]. Given that the aspirin moiety of PA-2 contains an acetyl group capable of acetylating multiple proteins in cancer cells [25], we examined the effect of PA-2 on the acetylation status of p53. In MDA-MB-231 cells, PA2 induced p53 acetylation at three distinct lysine residues (K373, K379 and K382) in a time-dependent manner; while in BT-20 cells PA-2 induced acetylation at $\mathrm{K} 373$ and $\mathrm{K} 379$ residues (Figure 6A). In MDA-MB-231 and BT-20 xenografts, treatment with PA-2 increased p53 acetylation at K382 and K373 residues, respectively (Figure 6A).

To further assess the role of p53 acetylation in cell death induction by PA-2, we overexpressed in MDA- 


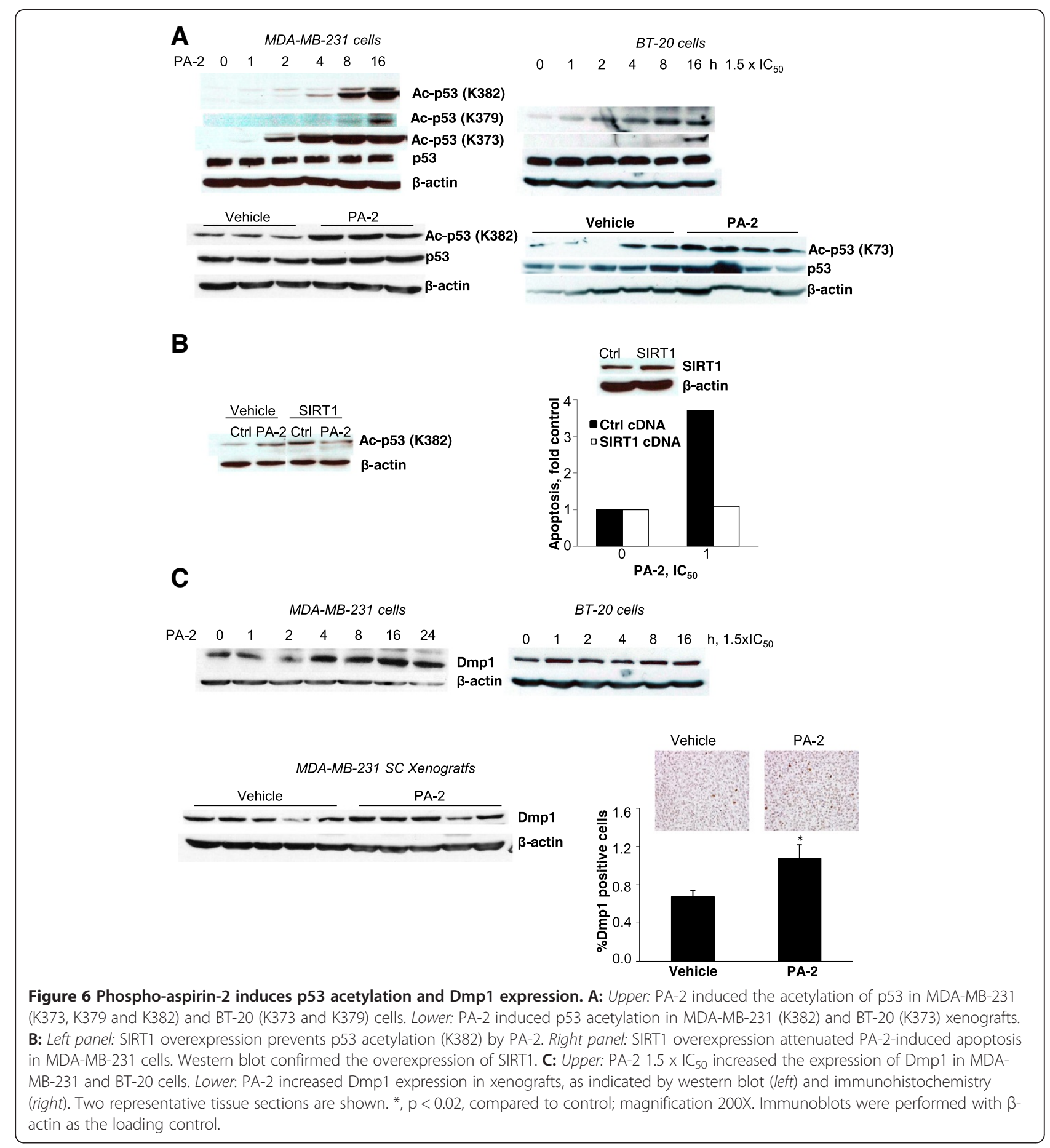

MB-231 cells SIRT1, which negatively regulates p53 through its de-acetylation [26,27]. Overexpression of SIRT1 blocked the ability of PA-2 to acetylate p53 at the K382 residue (Figure 6B). Importantly, SIRT1 overexpression attenuated the induction of apoptosis in response to PA-2 by $71 \%$, indicating that PA-2 induces apoptosis, at least in part, by a p53 acetylationdependent mechanism (Figure 6B).
PA-2 may also regulate p53 independently of acetylation. PA-2 significantly enhanced the expression of Dmp1, a tumor suppressor that induces p53-dependent cell cycle arrest by directly binding to its promoter [28]. Such an effect is observed in TNBC cells in vitro. In MDA-MB-231 xenografts, PA-2 treatment increased Dmp1 expression by $57 \%(\mathrm{p}<0.02)$ compared to the control group (Figure 6C). 


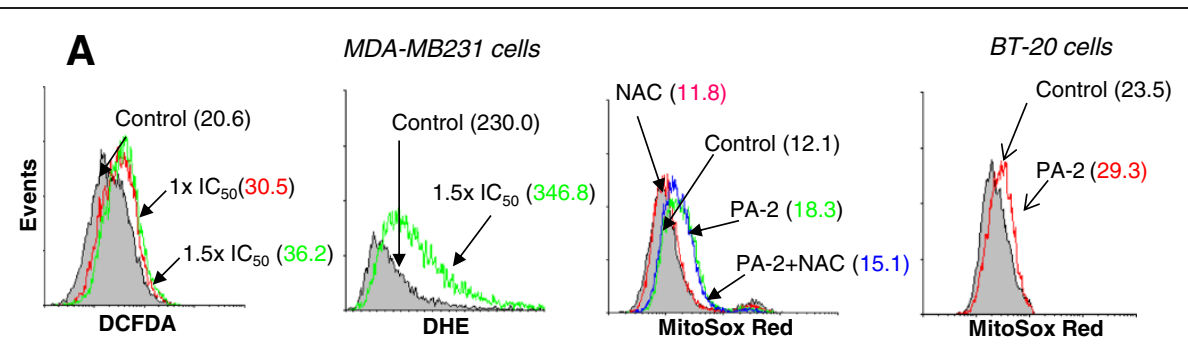

B
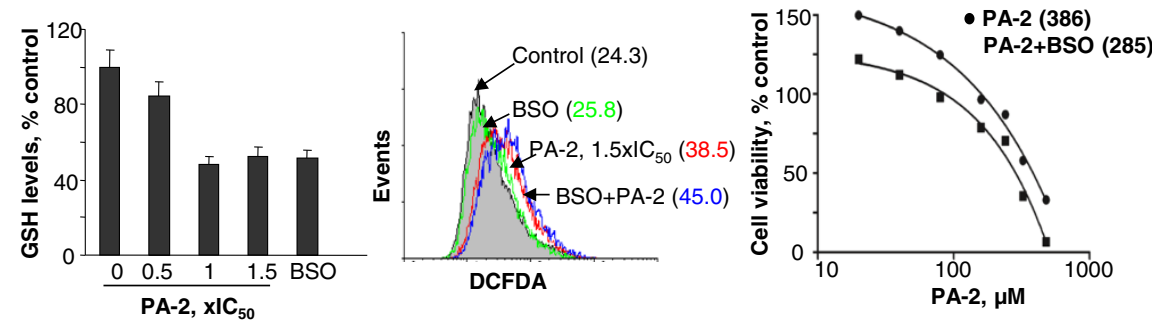

C
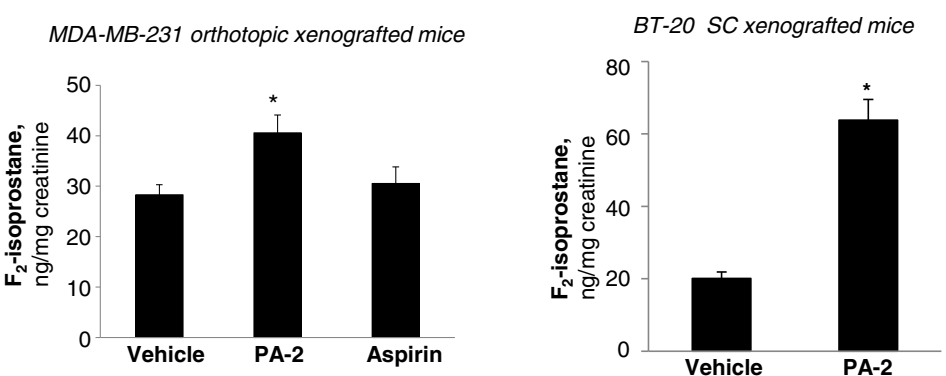

Figure 7 Phospho-aspirin-2 induces oxidative stress in TNBC. A: PA-2 induced RONS in MDA-MB-231 and BT-20 cells after $1 \mathrm{~h}$ treatment, as determined by DCFDA, DHE and MitoSOX Red staining and flow cytometry. B: Left panel: GSH level was suppressed in MDA-MB-231 cells treated with various concentrations of PA-2 for $24 \mathrm{~h}, \mathrm{BSO}$ as a positive control. Values are mean \pm SEM. Middle panel: PA-2 and BSO synergistically induced RONS. RONS production was determined by DCFDA staining in MDA-MB-231 cells treated with PA-2 or PA-2 plus BSO for 1 h. Right panel: PA-2 and BSO synergistically inhibited cell growth. Cell growth inhibition was determined by MTT in MDA-MB-231 cells treated with PA-2 or PA-2 plus BSO for 24h. C: PA-2 increased the levels of $15-F_{2 t}-$ Isoprostane in $24-h$ urine from nude mice bearing orthotopic MDA-MB231 $(p<0.05)$ and subcutaneous BT-20 xenografts $(p<0.006)$, while aspirin had no effect. Urinary $15-F_{2 t}-$ Isoprostane was determined using an ELISA kit, as described in Methods.

PA-2 induces RONS levels, inhibits the thioredoxin system and NF-KB activation

RONS play a significant role in the action of phosphoNSAIDs [29]. We determined the effect of PA-2 using various molecular probes: DCFDA (general RONS), DHE (cytoplasmic $\mathrm{O}_{2} \bullet^{-}$), and MitoSOX Red (mitochondrial $\left.\mathrm{O}_{2} \bullet^{-}\right)$. Compared to control, PA-2 $1.5 \times$ $\mathrm{IC}_{50}$ increased DCFDA by $76 \%$, DHE by $51 \%$ and MitoSOX Red by $51 \%$ in MDA-MB-231 cells (Figure $7 \mathrm{~A})$. $\mathrm{N}$-acetylcysteine (10 $\mathrm{mM})$, a ROS scavenger, partly blocked ROS induction by $26 \%$ in MDA-MB231 cells (Figure 7A). In BT-20 cells, PA-2 increased MitoSOX Red by $25 \%$. PA-2 1-1.5 $\times \mathrm{IC}_{50}$ also decreased the level of glutathione, a major cellular antioxidant. Co-incubation of PA-2 with BSO, an inhibitor of GSH synthesis, synergistically induced RONS levels and inhibited cell growth (Figure 7B).
To assess the effect of PA-2 on RONS in vivo, we measured urinary $15-\mathrm{F}_{2 \mathrm{t}}$-isoprostane, a marker of oxidative stress [30,31], in the mice bearing TNBC xenografts. In orthotopic MDA-MB-231 xenografts (Figure 2C), 15- $\mathrm{F}_{2 \mathrm{t}}$-isoprostane levels on day 25 were $28.7 \pm 3.3 \mathrm{ng} / \mathrm{mg}$ creatinine in controls and $40.9 \pm 2.2$ $\mathrm{ng} / \mathrm{mg}$ creatinine in the PA-2 group, representing a nearly $40 \%$ increase $(p<0.05)$ (Figure $7 C)$. In contrast, aspirin had no significant effect $(\mathrm{p}=0.6)$. In BT-20 xenografts, PA-2 treatment increased $15-\mathrm{F}_{2 \mathrm{t}}$-isoprostane levels by over 3 -fold over the control $(\mathrm{p}<0.006)$. Hence, PA-2, but not aspirin, induced RONS in vivo.

The thioredoxin ( $\operatorname{Trx})$ system, composed of thioredoxin reductase (TrxR) and Trx-1, plays an important role in redox homeostasis by reducing oxidized proteins; the latter is overexpressed in TNBC [32]. PA-2 inhibited TrxR activity in MDA-MB-231 cells in cell 

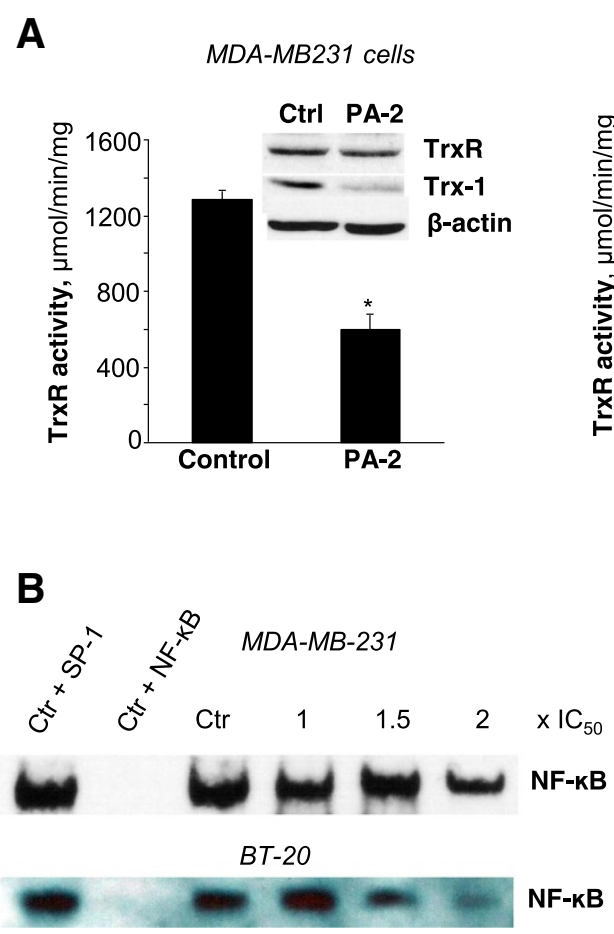

MDA-MB231 SC xenografts

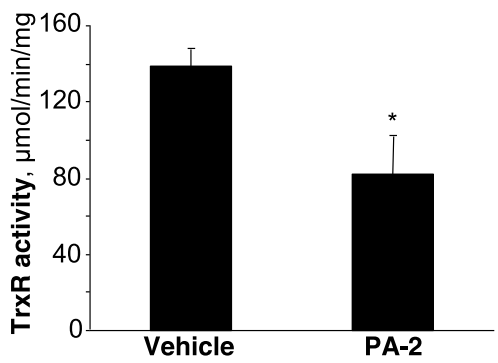

Figure 8 Phospho-aspirin-2 suppresses the thioredoxin (Trx) system and activation of NF-kB. A: Left panel: PA-2 $1.5 \times I C_{50}$ reduced TrxR activity in MDA-MB-231 cells after $1 \mathrm{~h}$ treatment. ${ }^{*}, \mathrm{p}<0.02$, compared to control. Immunoblots of TrxR and Trx-1 showed that PA-2 reduced the expression of Trx-1 in MDA-MB-231 cells. Right panel: PA-2 reduced TrxR activity in the protein lysates from MDA-MB-231 xenografts (treatment protocol) from animals treated with vehicle or PA-2 for 25 days. ${ }^{*}, \mathrm{p}<0.04$, compared to vehicle. B: Left panel: PA-2 inhibited constitutive NF-KB activation. EMSA for NF-KB of nuclear fractions isolated from MDA-MB-231 (upper) and BT-20 (lower) cells after $4 \mathrm{~h}$ treatment with or without PA-2 $1.5 \times I C_{50}$. To determine the specificity of the NF-KB transcription factor-DNA complex, the control nuclear fraction was incubated in the presence of 100 -fold molar excess of unlabeled oligonucleotide containing the consensus sequence for either the specific (+NF-KB) or an unspecific (+AP-1) transcription factor. Right panel: NF-kB (p-p65) levels from MDA-MB-231 tumors, determined by immunohistochemistry using an anti-p-p65 antibody, were reduced in PA-2 treated group compared to the vehicle control. The percentage of $p$-p65-positive cells in various fields was determined and averaged for each xenograft. ${ }^{*}, p<0.0009$, compared to vehicle. Representative images are shown; magnification 200X. All values are mean \pm SEM.

culture and MDA-MB-231 xenografts by $54 \%$ and $41 \%$, respectively $(\mathrm{p}<0.02-0.04)$, without affecting its levels (Figure 8A). PA-2 also significantly reduced Trx-1 levels in MDA-MB-231 cells after $1 \mathrm{~h}$ treatment with $1.5 \times \mathrm{IC}_{50}$ PA-2 (Figure 8A). These results indicate that PA-2 targets major components of the $\operatorname{Trx}$ system.

The Trx system is closely linked with the NF-kB signaling pathway. Trx-1 enhances DNA binding of NF- $\mathrm{KB}$ by reducing the intermolecular Cys62 -S-S- bond of its p50 subunit [33]. We thus examined the effect on PA-2 on NF-kB activation. Consistent with its inhibitory effect on Trx-1 expression, PA-2 also inhibited NF- $k B-$ DNA binding in a concentration-dependent manner in MDA-MB-231 and BT-20 cells (Figure 8B). A similar inhibition was observed in MDA-MB-231 xenografts. PA2 reduced the levels of activated p-p65 by $44 \%$ ( $<<$ 0.009 ), compared to the control group (Figure 8B).

\section{Discussion}

Our data demonstrate that PA-2, a novel derivative of aspirin, effectively inhibits TNBC in preclinical models and is much more potent than aspirin, its parent compound. The anticancer activity of PA-2 is associated with a pronounced effect on a) EGFR activation; b) p53 acetylation and c) RONS induction. These signaling effects of PA-2 culminate in the substantial inhibition of cell proliferation and induction of apoptosis, the net effect of which is a strong reduction in TNBC xenograft growth in vivo.

Efficacy and safety are the prime considerations in the evaluation of anticancer agents [34], and the latter is especially paramount in chemoprevention. Extensive epidemiological and clinical evidence supports a beneficial role of aspirin in the prevention of breast, colon, and lung cancers [35]; however, its gastrointestinal toxicity is limiting. Our results demonstrated that PA-2, 


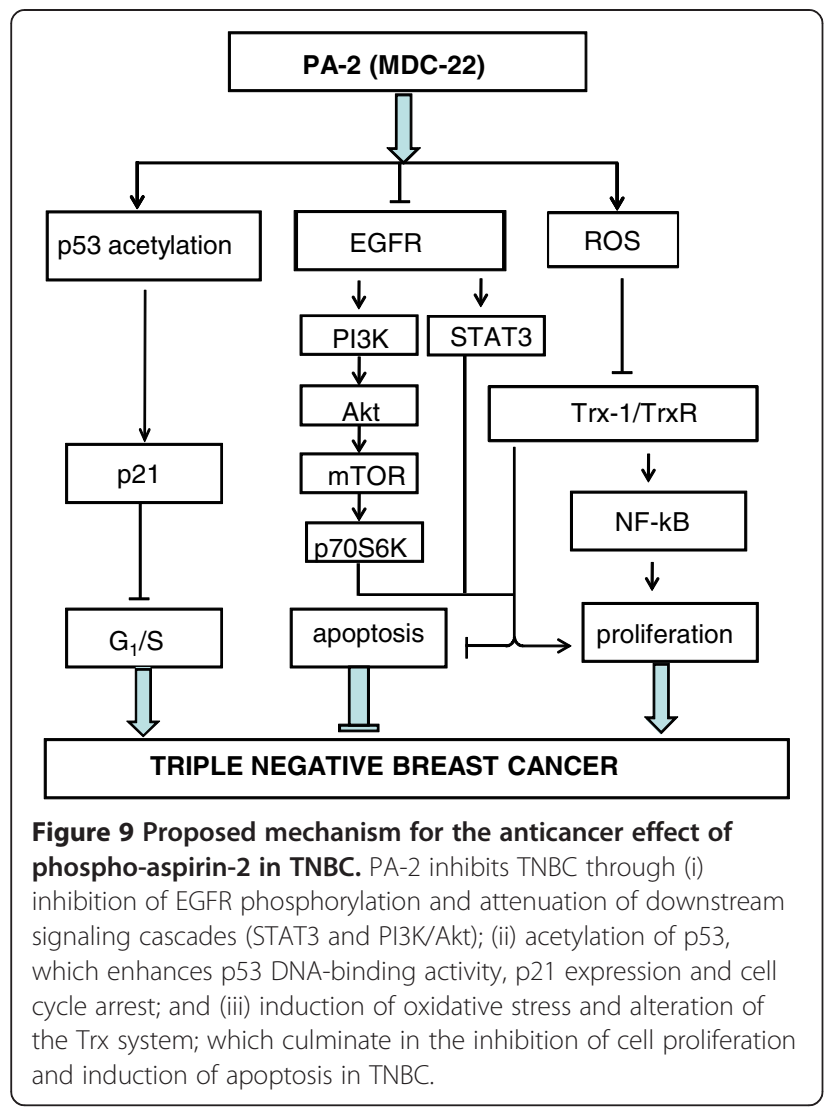

with the novel phospho-modification, is superior to aspirin both in terms of efficacy in TNBC, as well as safety [9]. PA-2, but not aspirin, administered in a chemoprevention protocol slowed the development of orthotopic MDA-MB-231 xenografts.

PA-2 is highly efficacious when used in the treatment setting and its chemotherapeutic effect is even stronger than its chemopreventive effect. PA-2 potently inhibits TNBC in vivo, almost completely arresting the growth of both MDA-MB-231 and BT-20 xenografts. Consistent with its strong chemotherapeutic efficacy, PA-2 induced a profound cytokinetic effect involving inhibition of cell proliferation and induction of apoptosis. Hence, PA-2 is a promising anticancer candidate that merits further evaluation.

Our work identified EGFR, p53 and RONS as the major signaling mechanisms (Figure 9) involved in eliciting the growth inhibitory effect of PA-2. EGFR is overexpressed in 16-48\% of breast cancers and its expression is associated with poor prognosis [36,37]. In particular, EGFR is frequently overexpressed in TNBC, a subset of breast cancer that is characterized by their unique molecular profile, aggressive behavior and distinct patterns of metastasis [38]. PA-2 is an inhibitor of EGFR phosphorylation in vitro and in vivo. The inhibitory effect of PA-2 appears to be mediated by a novel mechanism involving the inhibition of ADAM17, a major protease that controls availability of EGFR ligands [39]. A key consequence of PA-2induced inhibition of EGFR is the suppression of prosurvival STAT3 and PI3K and the sequential inactivation of their downstream signaling propagation, thereby causing growth inhibition and cell death.

Mutations of p53 are exceptionally frequent in TNBC $(>80 \%)$ and its inactivation predicts poor survival in TNBC patients $[10,12]$. Activation-inactivation of p53 depends on a repertoire of post-translational modifications [40], including phosphorylation and acetylation. p53 acetylation was found to be indispensable for its activation, as it destabilizes the p53-MDM2 interaction, thereby abrogating MDM2-mediated transcription repression [24]. Here, we show that PA-2 acetylates p53 in vitro and in vivo and disrupts its association with MDM2, which in turn, enhances p53-DNA binding activity. Forced deacetylation of p53 partly attenuated cell death induction by PA-2, indicating an important role of p53 acetylation in mediating the effect of PA-2. PA-2 additionally regulates p53 independently of acetylation. Dmp1 is a transcription factor that physically interacts with p53 [41]. Dmp1-p53 binding antagonizes the ubiquitination of $\mathrm{p} 53$ byMDM-2 and promotes the nuclear translocation of p53 [28]. PA-2 enhanced the expression of Dmp1 in TNBC cells and in xenografts, which may further contribute to the robust p53 activation triggered by PA- 2 .

The induction of oxidative stress plays a key role in the anticancer effect of structurally related phosphoNSAIDs $[9,42]$. PA-2 induces oxidative stress in TNBC cells in culture and in xenografts by compromising cellular antioxidant defense mechanisms. First, PA-2 suppressed the Trx system, with both TrxR and Trx-1 affected in a significant way. TrxR and Trx-1 are critical components of the cellular redox system [43]. Trx1 reduces client proteins oxidized by RONS, with itself undergoing oxidation, while $\operatorname{Trx} \mathrm{R}$ regenerates the reduced Trx-1. In TNBC cells and xenografts, PA-2 inhibited TrxR activity and decreased the expression of Trx-1. Second, PA-2 significantly reduced intracellular levels of GSH, the major chemical antioxidant of mammalian cells. Induction of oxidative stress has major repercussions on redox- and Trx-dependent signaling cascades, as exemplified by the inhibitory effect on NF$\kappa B$. NF- $\mathrm{KB}$ is constitutively active in TNBC [44], and its aberrant activation is linked to inflammation and cancer. Induction of oxidative stress and the subsequent inhibition of NF-KB by PA-2 may mediate part of its growth inhibitory effect.

It is of interest that PA-2 has superior efficacy compared to conventional aspirin, the starting compound for its synthesis. The reasons for this difference are 
not entirely clear, but as a new chemical entity, PA-2 is expected to have distinct properties from its parent compound. Perhaps the most relevant property of these two compounds is their ability to induce oxidative stress, an effect that accounts for much of the anticancer efficacy of phospho-NSAIDs, including phosphoaspirin [29]. Indeed, PA-2 caused robust oxidative stress in mice, reflected in enhanced urinary levels of the biomarker $\mathrm{F}_{2}$-isoprostane. In contrast, aspirin failed to produce such an effect, and this difference explains to a large extent their differential efficacy. Additional mechanistic differences might also contribute, especially with regards to effects on cell signaling cascades.

\section{Conclusions}

Our work indicates that PA-2 possesses chemotherapeutic and chemopreventive efficacy against TNBC in preclinical models, and establishes inhibition of EGFR, acetylation of p53 and induction of oxidative stress as critical mediators of its mechanism of action (Figure 9). The multi-targeted nature of PA-2 towards the dysregulated signaling cascades in TNBC further suggests the notion that PA-2 may be a promising therapeutic option, either alone or in combination with other therapies.

\section{Additional file}

Additional file 1: Table S1. Antibody microarray analysis on phosphor-aspirin treated MDA-MB-231 cells. TNBC MDA-MB-231 cells treated with vehicle or PA-2 $1.5 \times \mathrm{IC}_{50}$ for $2 \mathrm{~h}$ were performed antibody microarray analysis by Kinexus (Vancouver, CA).

\section{Abbreviations}

ADAM: A disintegrin and metalloproteinase; Akt: Protein kinase B; EGFR: Epidermal growth factor receptor; ER: Estrogen receptor; mTOR: Mammalian target of rapamycin; NSAID: Nonsteroidal anti-inflammatory drug; NF-KB: Nuclear factor kappa-light-chain-enhancer of activated B cells; PA-2: Phospho-aspirin-2; PI3K: Phosphoinositide 3-kinase; PR: Progesterone receptor; RONS: Reactive oxygen and nitrogen species; SIRT1: Sirtuin; STAT3: Signal transducer and activator of transcription 3; Trx-1: Thioredoxin-1; TrxR: Thioredoxin reductase; SC: Subcutaneous.

\section{Competing interests}

The authors have nothing to disclose except for BR, who has an equity position in Medicon Pharmaceuticals, Inc. and NO who is an employee for the same.

\section{Authors' contributions}

$\mathrm{LH}$ conceived the study, participated in its design, carried out most of the in vitro and in vivo studies, analyzed the data and participated in the preparation of the manuscript. YS participated in the study design, performed the orthotopic transplantation of breast cancer cells and involved in the drafting the manucript; CCW, GGM, KWC participated in the study design, data analyses and writing of the manuscript. KV synthesized batches of PA-2, participated in the study design and data analysis. NA performed the luciferase imaging of breast tumors, participated in data collection and data analysis. NO performed the immunohistochemical analyses, participated in data collection and data analysis. BR participated in the study design, supervised the work, analyzed data and participated in writing the manuscript. All authors read and approved the final manuscript.

\section{Acknowledgement}

Grant support: NIH grants R01-CA139453, R01CA13945402 and 1N01CN43302WA22 and HHSN261201000109C.

\section{Author details}

'Division of Cancer Prevention, Department of Medicine, Stony Brook University, Stony Brook, New York 11794-8173, USA. ${ }^{2}$ Medicon

Pharmaceuticals, Inc, Setauket, NY 11733, USA.

Received: 17 December 2013 Accepted: 21 February 2014

Published: 28 February 2014

\section{References}

1. Siegel R, Naishadham D, Jemal A: Cancer statistics, 2012. CA Cancer J Clin 2012, 62(1):10-29.

2. Rinsema TJ: One hundred years of aspirin. Med Hist 1999, 43(4):502-507.

3. Stanley P, Hegedus R: Aspirin-the first hundred years. Biologist (London) 2000, 47(5):269-271.

4. Baron JA: What now for aspirin and cancer prevention? J Natl Cancer Inst 2004, 96(1):4-5.

5. Baron JA, Cole BF, Sandler RS, Haile RW, Ahnen D, Bresalier R, McKeownEyssen G, Summers RW, Rothstein R, Burke CA, Snover DC, Church TR, Allen Jl, Beach M, Beck GJ, Bond JH, Byers T, Greenberg ER, Mandel JS, Marcon N, Mott LA, Pearson L, Saibil F, van Stolk RU: A randomized trial of aspirin to prevent colorectal adenomas. N Engl J Med 2003, 348(10):891-899.

6. Marshall SF, Bernstein L, Anton-Culver H, Deapen D, Horn-Ross PL, Mohrenweiser H, Peel D, Pinder R, Purdie DM, Reynolds P, Stram D, West D, Wright WE, Ziogas A, Ross RK: Nonsteroidal anti-inflammatory drug use and breast cancer risk by stage and hormone receptor status. $J$ Natl Cancer Inst 2005, 97(11):805-812.

7. Piazza GA, Keeton AB, Tinsley HN, Gary BD, Whitt JD, Mathew B, Thaiparambil J, Coward L, Gorman G, Li Y, Sani B, Hobrath JV, Maxuitenko YY, Reynolds RC: A novel sulindac derivative that does not inhibit cyclooxygenases but potently inhibits colon tumor cell growth and induces apoptosis with antitumor activity. Cancer Prev Res (Phila) 2009, 2(6):572-580.

8. Wong CC, Cheng KW, Xie G, Zhou D, Zhu CH, Constantinides PP, Rigas B: Carboxylesterases 1 and 2 hydrolyze phospho-nonsteroidal antiinflammatory drugs: relevance to their pharmacological activity. $J$ Pharmacol Exp Ther 2012, 340(2):422-432.

9. Huang L, Mackenzie G, Ouyang N, Sun Y, Xie G, Johnson F, Komninou D, Rigas B: The novel phospho-non-steroidal anti-inflammatory drugs, OXT-328, MDC-22 and MDC-917, inhibit adjuvant-induced arthritis in rats. Br J Pharmacol 2011, 162(7):1521-1533.

10. Gasco M, Shami S, Crook T: The p53 pathway in breast cancer. Breast Cancer Res 2002, 4(2):70-76.

11. Price JT, Tiganis T, Agarwal A, Djakiew D, Thompson EW: Epidermal growth factor promotes MDA-MB-231 breast cancer cell migration through a phosphatidylinositol 3'-kinase and phospholipase C-dependent mechanism. Cancer Res 1999, 59(21):5475-5478.

12. Cancer Genome Atlas Network: Comprehensive molecular portraits of human breast tumours. Nature 2012, 490(7418):61-70.

13. Dancey JE, Freidlin B: Targeting epidermal growth factor receptor-are we missing the mark? Lancet 2003, 362(9377):62-64.

14. Vousden $\mathrm{KH}$, Prives $\mathrm{C}$ : Blinded by the light: the growing complexity of p53. Cell 2009, 137(3):413-431.

15. Zhao W, Mackenzie GG, Murray OT, Zhang Z, Rigas B: Phosphoaspirin (MDC-43), a novel benzyl ester of aspirin, inhibits the growth of human cancer cell lines more potently than aspirin: a redox-dependent effect. Carcinogenesis 2009, 30(3):512-519.

16. Mackenzie GG, Sun Y, Huang L, Xie G, Ouyang N, Gupta RC, Johnson F, Komninou D, Kopelovich L, Rigas B: Phospho-sulindac (OXT-328), a novel sulindac derivative, is safe and effective in colon cancer prevention in mice. Gastroenterology 2010, 139(4):1320-1332.

17. Hundley TR, Gilfillan AM, Tkaczyk C, Andrade MV, Metcalfe DD, Beaven MA: Kit and FcepsilonRI mediate unique and convergent signals for release of inflammatory mediators from human mast cells. Blood 2004, 104(8):2410-2417.

18. Ouyang N, Williams JL, Rigas B: NO-donating aspirin isomers downregulate peroxisome proliferator-activated receptor (PPAR)\{delta\} expression in APCmin/+ mice proportionally to their tumor inhibitory 
effect: Implications for the role of PPAR \{delta\} in carcinogenesis. Carcinogenesis 2006, 27(2):232-239.

19. Rigas B, Kozoni V: The novel phenylester anticancer compounds: Study of a derivative of aspirin (phoshoaspirin). Int J Oncol 2008, 32(1):97-100.

20. Likhite V: Aspirin and Breast Cancer: Studies In Mice. In Central Reginoal Meeting of the American Chemical Society. Cleveland, Ohio; 2009.

21. Baumgart A, Seidl S, Vlachou P, Michel L, Mitova N, Schatz N, Specht K, Koch I, Schuster T, Grundler R, Kremer M, Fend F, Siveke JT, Peschel C, Duyster J, Dechow T: ADAM17 regulates epidermal growth factor receptor expression through the activation of Notch1 in non-small cell lung cancer. Cancer Res 2010, 70(13):5368-5378.

22. Soussi T, Lozano G: p53 mutation heterogeneity in cancer. Biochem Biophys Res Commun 2005, 331(3):834-842.

23. Meek DW, Anderson CW: Posttranslational modification of $\mathrm{p} 53$ : cooperative integrators of function. Cold Spring Harb Perspect Biol 2009, 1(6):a000950.

24. Tang Y, Zhao W, Chen Y, Zhao Y, Gu W: Acetylation is indispensable for p53 activation. Cell 2008, 133(4):612-626.

25. Marimuthu S, Chivukula RS, Alfonso LF, Moridani M, Hagen FK, Bhat GJ: Aspirin acetylates multiple cellular proteins in HCT-116 colon cancer cells: identification of novel targets. Int J Oncol 2011, 39(5):1273-1283.

26. Ito A, Kawaguchi Y, Lai CH, Kovacs JJ, Higashimoto Y, Appella E, Yao TP: MDM2-HDAC1-mediated deacetylation of p53 is required for its degradation. EMBO J 2002, 21(22):6236-6245.

27. Solomon JM, Pasupuleti $R, X u$ L, McDonagh T, Curtis R, DiStefano PS, Huber L: Inhibition of SIRT1 catalytic activity increases p53 acetylation but does not alter cell survival following DNA damage. Mol Cell Biol 2006, 26(1):28-38

28. Taneja P, Maglic D, Kai F, Sugiyama T, Kendig RD, Frazier DP, Willingham $M C$, Inoue K: Critical roles of DMP1 in human epidermal growth factor receptor 2/neu-Arf-p53 signaling and breast cancer development. Cancer Res 2010, 70(22):9084-9094.

29. Sun Y, Huang L, Mackenzie GG, Rigas B: Oxidative stress mediates through apoptosis the anticancer effect of phospho-nonsteroidal antiinflammatory drugs: implications for the role of oxidative stress in the action of anticancer agents. J Pharmacol Exp Ther 2011, 338(3):775-783.

30. Basu S: F2-isoprostanes in human health and diseases: from molecular mechanisms to clinical implications. Antioxid Redox Signal 2008, 10(8):1405-1434

31. Tacconelli S, Capone ML, Patrignani P: Measurement of 8-isoprostaglandin F2alpha in biological fluids as a measure of lipid peroxidation. Methods Mol Biol 2010, 644:165-178.

32. Mukherjee A, Martin SG: The thioredoxin system: a key target in tumour and endothelial cells. Br J Radiol 2008, 81(Spec No 1):S57-S68.

33. Matthews JR, Wakasugi N, Virelizier JL, Yodoi J, Hay RT: Thioredoxin regulates the DNA binding activity of NF-kappa $B$ by reduction of a disulphide bond involving cysteine 62. Nucleic Acids Res 1992 20(15):3821-3830.

34. Wong CC, Cheng KW, Rigas B: Preclinical predictors of anticancer drug efficacy: critical assessment with emphasis on whether nanomolar potency should be required of candidate agents. J Pharmacol Exp Ther 2012, 341(3):572-578.

35. Cuzick J, Otto F, Baron JA, Brown PH, Burn J, Greenwald P, Jankowski La Vecchia C, Meyskens F, Senn HJ, Thun M: Aspirin and non-steroidal anti-inflammatory drugs for cancer prevention: an international consensus statement. Lancet Oncol 2009, 10(5):501-507.

36. Tsutsui S, Kataoka A, Ohno S, Murakami S, Kinoshita J, Hachitanda Y: Prognostic and predictive value of epidermal growth factor receptor in recurrent breast cancer. Clin Cancer Res 2002, 8(11):3454-3460.

37. Tsutsui S, Ohno S, Murakami S, Hachitanda Y, Oda S: Prognostic value of epidermal growth factor receptor (EGFR) and its relationship to the estrogen receptor status in 1029 patients with breast cancer. Breast Cancer Res Treat 2002, 71(1):67-75.

38. Nielsen TO, Hsu FD, Jensen K, Cheang M, Karaca G, Hu Z, HernandezBoussard T, Livasy C, Cowan D, Dressler L, Akslen LA, Ragaz J, Gown AM, Gilks CB, van de Rijn M, Perou CM: Immunohistochemical and clinical characterization of the basal-like subtype of invasive breast carcinoma. Clin Cancer Res 2004, 10(16):5367-5374.

39. Sternlicht MD, Sunnarborg SW: The ADAM17-amphiregulin-EGFR axis in mammary development and cancer. J Mammary Gland Biol Neoplasia 2008, 13(2):181-194
40. Walerych D, Napoli M, Collavin L, Del Sal G: The rebel angel: mutant p53 as the driving oncogene in breast cancer. Carcinogenesis 2012, 33(11):2007-2017.

41. Frazier DP, Kendig RD, Kai F, Maglic D, Sugiyama T, Morgan RL, Fry EA, Lagedrost SJ, Sui G, Inoue K: Dmp1 physically interacts with p53 and positively regulates $\mathrm{p} 53$ 's stability, nuclear localization, and function. Cancer Res 2012, 72(7):1740-1750.

42. Sun Y, Rigas B: The thioredoxin system mediates redox-induced cell death in human colon cancer cells: implications for the mechanism of action of anticancer agents. Cancer Res 2008, 68(20):8269-8277.

43. Kim SJ, Miyoshi Y, Taguchi T, Tamaki Y, Nakamura H, Yodoi J, Kato K, Noguchi S: High thioredoxin expression is associated with resistance to docetaxel in primary breast cancer. Clin Cancer Res 2005, 11(23):8425-8430.

44. Yamamoto M, Taguchi Y, Ito-Kureha T, Semba K, Yamaguchi N, Inoue J: NF-kappaB non-cell-autonomously regulates cancer stem cell populations in the basal-like breast cancer subtype. Nat Commun 2013, 4:2299.

doi:10.1186/1471-2407-14-141

Cite this article as: Huang et al.: Phospho-aspirin (MDC-22) inhibits breast cancer in preclinical animal models: an effect mediated by EGFR inhibition, p53 acetylation and oxidative stress. BMC Cancer 2014 14:141.

\section{Submit your next manuscript to BioMed Central and take full advantage of:}

- Convenient online submission

- Thorough peer review

- No space constraints or color figure charges

- Immediate publication on acceptance

- Inclusion in PubMed, CAS, Scopus and Google Scholar

- Research which is freely available for redistribution 